\title{
Free Modal Analysis for Spiral Bevel Gear Wheel Based on the Lanczos Method
}

\author{
Xiang Tieming ${ }^{*}, 1,2$, Zhou Shuiting ${ }^{1}$ and Yi Liao ${ }^{1}$ \\ ${ }^{I}$ School of Mechanical \& Automotive Engineering, Xiamen University of Technology, Xiamen, 361024, China \\ ${ }^{2}$ College of Mechanical Engineering and Automation, Huaqiao University, Xiamen, 361021, China
}

\begin{abstract}
In order to obtain the spiral bevel gear wheel natural frequencies and mode shapes in the unconstrained state for the purpose of dynamic characteristics study, the spiral bevel gear wheel three-dimensional solid model of a mini-bus main reducer is established in this paper. The finite element model of spiral bevel gear wheel which consists of 32351 nodes, 18436 solid187 tetrahedrons finite element method elements is established by using free grid meshing method in this paper. Extract the first 6 orders modals parameters such as natural frequencies and main vibration mode shapes by using the Lanczos method. The new $1^{\text {st }}$ to $4^{\text {th }}$ orders modals are formed by comparing and merging 2 orders repeated modals. In order to verify the effectiveness of the finite element analysis results, the experiment modal test based on the impulse force hammer percussion transient single-point excitation and multi-point response analysis method has been done. The maximum difference value of natural frequency between experimental modal test result and finite element modal analysis results is $29.86 \mathrm{~Hz}$, the maximum error rate is $0.41 \%$, which confirmed the result of finite element method is effective and reliable. The conclusions reflect the vibration response characteristics of spiral bevel gear wheel, and provide theoretical basis for dynamic response, structure design and optimization of spiral bevel gear wheel.
\end{abstract}

Keywords: Experiment modal test, free modal, Lanczos method, mode shape, natural frequency, spiral bevel gear.

\section{INTRODUCTION}

Spiral bevel gear with the good advantages of stable transmission, low noise, high contact coincidence ratio, is suitable for application on the automobile main reducer. But the vibration, shock and noise problems [1] caused by spiral bevel gear work conditions of high speed and heavy load influence the ride comfort, manipulation stability and fuel economy of the automobile [2].

Modal analysis is a basis of transient dynamic analysis, load prediction, spectrum analysis, modal superposition method for response (to determine the fatigue life, dynamic strength etc.), vibration control, vibration acoustic characteristics estimation and control, fault vibration and prediction and dynamic optimization design [3-5]. Obtained the natural frequency of the structure by modal analysis can avoid the occurrence of resonance phenomenon, and provide some measures to reduced vibration, shock and noise. It is difficult to establish a real constraint conditions and the incentives are very complex during the finite element constraint modal analysis for the spiral bevel gear wheel, because of the spiral bevel gear wheel with very complex constraint conditions, while the free modal itself reflects the spiral bevel gear wheel inherent dynamic characteristics [6-9], so the free modal analysis of a mini bus main reducer spiral bevel gear wheel has been done in this paper.

*Address correspondence to this author at the Xiamen University of Technology, Xiamen city, Fujian Province, 361024, China;

Tel: +86 0592-6291072; E-mail: xtm502@163.com
There are mainly Lanczos method, Subspace method [1017], Power dynamics method [18]. Reduced/ Householder [19], Unsymmetric method [20], Damp method and QR damping method [21] etc., which extract the modal parameters by using the finite element method. The Lanczos modal extraction method use three iterative formula to produces a set of orthonormal eigenvectors, convert the original matrix of real symmetric positive definited into a tridiagonal matrix $[17,22-26]$ the modal extraction problem is transformed to eigenvalue and eigenvector solving problem of a tridiagonal matrix [27-33]. The Lanczos method with the smaller amount of computation, faster convergence speed [34-35], faster calculation speed and higher accuracy, is suitable for solid element and shell element in finite element analysis, and has been regarded as the most effective algorithms for solving the large sparse matrix eigenvalue problem [36-41].

\section{THE THEORY BASIC OF FREE MODAL ANALYSIS}

\subsection{Vibration Differential Equation}

According to the vibration theory, the vibration differential equation of $\mathrm{n}$ degrees of freedom elastic system can be described in the physical coordinates as follow [42].

$$
M \ddot{X}+C \dot{X}+K X=F(t)
$$

where, $M$ is the mass matrix, $C$ is the damping matrix, $K$ is the stiffness matrix, $X$ is the displacement column vectors, 
$\dot{X}$ is the speed column vector, $\ddot{X}$ is the acceleration column vector, $f(t)$ is the excitation force column vector.

For the free vibration system of non damping or can negligible damping with no external excitation force, substitute the equation $f(t)=0$ into Eq. (1) can obtain the free vibration differential equation of $\mathrm{n}$ degrees of freedom elastic system as follow.

$M \ddot{X}+K X=0$

Generally, Eq. (1) and Eq. (2) described by the physical coordinates are coupled with each other, in order to obtain the independent equations described by modal coordinates and modal parameters, it's necessary to carry out the vibration differential equation as shown in Eq. (2) a series of coordinate transformation, which transform the physical coordinate into modal coordinates, and makes the vibration differential equations decoupled, the homogeneous equations can be obtained as following shown.

$\left(K-\omega_{i}^{2} M\right) \varphi_{i}=0$

where, $\omega_{i}$ is the $\mathrm{i}^{\text {th }}$ order natural frequency of the system, $\varphi_{i}$ is the $\mathrm{i}^{\text {th }}$ order main vibration vectors of the system, $\mathrm{i}=1$, $2, \ldots \ldots \mathrm{n}$.

The process of solving $\omega_{i}$ and $\varphi_{i}$ is the process of modal analysis. The non damping free vibration equation Eq. (3) described by the modal coordinates has $\mathrm{n}$ orders natural frequencies $\omega_{n}$ (possible value) and the corresponding $\mathrm{n}$ orders main modal vectors $\varphi_{n}$, for each group of natural frequency $\omega_{i}$ and the corresponding main vibration vectors $\varphi_{i}$ are represents a freedom vibration shape (modal) of single-degree, the free vibration shape of multi-degree system can be decomposed into a linear superposition of single-degree free vibration shape, that is to say the $n$ degrees free vibration system is composed by linear combinations of $\mathrm{n}$ number of inherent vibration modal, therefore, any vibration form of the system is a superposition of the $\mathrm{n}$ number of main vibration modal. The lower order vibration modal of the system has the more prominent contribution rate and determines the dynamic response characteristics of the system, so, we should more focus on the lower order modal while the higher order modals is often not easy to stimulate [2]. Therefore, the $1^{\text {st }}$ to $12^{\text {th }}$ orders modals natural frequencies and vibration modals of the spiral bevel gear wheel are extracted in this paper.

\subsection{Lanczos Numerical Calculation Method}

The solution of the free vibration differential Eq. (2) can be written in the form of

$K \Phi=\omega^{2} M \Phi$

where, $\Phi=\left\{\varphi_{1}, \varphi_{2}, \cdots \varphi_{i}, \cdots \varphi_{n}\right\}$.

Eq. (4) is a generalized eigenvalue problem. For the multi-degree of freedom constraints system with non rigid motion, the stiffness matrix $K$ is real symmetric positive definite matrix which can be carried out Cholesky factor decomposition by using the square root method [43-46], the Eq. (4) can be rewritten in the form of

$A Y=\mu Y$

where $K=L L^{T}$ ( $L$ is a lower triangular matrix), $\mu=1 / \omega^{2}$, $A=L^{-1} M L^{-T}, Y=L^{T} \Phi$.

And for the multi-degree of freedom system with rigid body motion, the stiffness matrix $K$ is positive semi-definite matrix which can transform it into positive definite matrix by the shift method, and then carry out the Cholesky factor decomposition. $K$ and $\mu$ are determined by the Eq. (6).

$\left\{\begin{array}{l}K+\rho M=L L^{T} \\ \mu=1 /\left(\omega^{2}+\alpha\right)\end{array}\right.$

where, $\rho(\rho>0)$ is a constant.

The characteristics solutions of Eq. (5) are characteristics solution of Eq. (4) through a series of matrix transformations. Matrix A shown in Eq. (5) can convert into tridiagonal matrix by the Eq. (7) through selecting the initial Lanczos iterative vector $V_{i}$ which should satisfy the condition $V_{i}^{T} V_{i}=I$, where $I$ is an unit matrix [17, 47-49].

$V^{T} A V Q=\mu V^{T} V Q$

where, $V Q=Y$, and:

$V^{T}=V^{-1}$

The matrix $V^{T} A V=T$ is a three diagonal matrix, $V^{T} A V$ can be written as follow:

$V^{T} A V Q=T=\left[\begin{array}{cccccc}\alpha_{1} & \beta_{1} & & & & \\ \beta_{1} & \alpha_{2} & \beta_{2} & & & \\ & \beta_{2} & \alpha_{3} & \beta_{3} & & \\ & & \ddots & \ddots & \ddots & \\ & & & \ddots & \ddots & \beta_{n-1} \\ & & & & \beta_{n-1} & \alpha_{n}\end{array}\right]$

The following equation can been obtained by combining the Eq. (8) and Eq. (9).

$A V=V T$

The vector $V_{i+l}$ is orthogonal with the former two vectors $V_{i}, V_{i-1}$, and the Eq. (10) can be expressed as follows [47-49]:

$A V=\beta_{i-1} V_{i-1}+\alpha_{i} V_{i}+\beta_{i} V_{i+1}$

where, $\alpha_{i}, \beta_{i}$ and $V_{i+1}$ can be obtained by the Eq. (12) respectively.

$\left\{\begin{array}{l}\alpha_{i}=V_{i}^{T}\left(A V_{i}-\beta_{i-1} V_{i}\right) \quad\left(\beta_{0}=0\right) \\ \beta_{i}=\left(C_{i}^{T} C_{i}\right)^{1 / 2} \quad\left(C_{i}=A V_{i}-\beta_{i-1} V_{i-1}-\alpha_{i} V_{i}\right) \\ V_{i+1}=\left(1 / \beta_{i}\right) C_{i}\end{array}\right.$

After the completion of iterative process can form $\mathrm{m}$ number of Lanczos vectors $V_{i}(i=1,2, \cdots, m)$, number $m$ is 2 times to the order of eigenvalues to be solved.

Solve the Eq. (8) based on the Sturm dichotomy theory can get the characteristics value solutions of specified order 
[50, 51]. Generally, the Eq. (9) cannot get all the characteristics value ( $n$ orders), only need to be truncated to $m$ orders $(m<n$, $m$ is usually 2 times to the order of eigenvalues to be solved). Solving the eigenvalue problem can be expressed as the following Eq. (13) shown:

$$
T_{m} Z=\mu_{i} T
$$

where, $\mu_{i}$ is the characteristics value obtained by truncating the three diagonal matrix.

After obtained the characteristics value $\mu_{i}$ by using the dichotomy method to solve the Eq. (13), the characteristics vector $Z$ in the Eq. (13) can obtain by inverse iteration, and then can obtain the characteristic vector $Y$ of characteristic equation Eq. (5) by equation $Y=V Z$, then by equation $\Phi=L^{-T} Y$ can get the original characteristics vector $\Phi$ and characteristics values $\omega_{i}^{2}=1 / \mu_{i}(i=1,2, \cdots, m)$ of the Eq. (4).

In order to improve the stability of the iterative algorithm, the Lanczos vector sequence orthogonal method [52-54] was introduced, and suppose the following equation is established firstly.

$P_{i}=I-2\left\{q_{i}\right\}\left\{q_{i}\right\}^{T}$

where, $I$ is an unit matrix, the (i-1) th element of vector $\left\{q_{i}\right\}$ is zero, and $\left\|q_{i}\right\|=1$.

For $1 \leq i \leq m$, the following formula can be established:

$$
\left\{\begin{array}{l}
\{w\}_{i+1}=P_{i} P_{i-1} \cdots P_{1} C_{i} \\
P_{i+1}\{w\}_{i+1}=\gamma\left\{e_{i+1}\right\} \\
V_{i+1}=P_{1} P_{2} \cdots P_{i+1}\left\{e_{i+1}\right\}
\end{array}\right.
$$

where, $\left\{e_{i}\right\}$ is the $i^{t h}$ column of the unit matrix, and $\gamma_{i}=\beta_{i}$.

Solve the characteristic vector $Y$ of matrix $A$ in Eq. (5) by Eq. (14), get the original characteristic vector $\Phi$ and characteristic value $\omega_{i}^{2}=1 / \mu_{i}(i=1,2, \cdots, m)$ by the equation $\Phi$ $=L^{-T} Y$.

\section{FINITE ELEMENT MODAL}

There are a pair of spiral bevel gears installed on a mini bus main reducer, some parameters are shown in Table $\mathbf{1 .}$ The three-dimensional model of spiral bevel gear wheel was established in the UG NX software. The middle part of the spiral bevel gear wheel was hollowed for installation of a differential according to the need of the actual work condition. Design $8 *$ M10 threaded hole with $18 \mathrm{~mm}$ deep on the semifinished product of spiral bevel gear wheel for power output connecting with the differential case.

Export the spiral bevel gear wheel model established in UG NX as Parasolid file format, then import the exported file to ANSYS Workbench platform. The geometric model is shown in Fig. (1).

Define the material property of spiral bevel gear wheel and mesh the grid, the finite element model was established as shown in Fig. (2).
Table 1. Some parameters of spiral bevel gear wheel.

\begin{tabular}{|c|c|c|}
\hline Parameters & Symbol/Unit & Wheel \\
\hline \hline Number of teeth & $\mathrm{z}$ & 37 \\
\hline Exterior transverse modulus & $\mathrm{m} / \mathrm{mm}$ & 4.5 \\
\hline Shaft angle & $\sum /\left(^{\circ}\right)$ & 90 \\
\hline Reference cone angle & $\delta /\left(^{\circ}\right)$ & 76.3287 \\
\hline Face width & $\mathrm{b} / \mathrm{mm}$ & 28 \\
\hline Rotation direction & & Right \\
\hline Pitch circle diameter & $\mathrm{d} / \mathrm{mm}$ & 166.5 \\
\hline Pressure angle & $\alpha_{\mathrm{n}} /\left(^{\circ}\right)$ & 20 \\
\hline Spiral angle & $\beta_{\mathrm{m}} /\left(^{\circ}\right)$ & 35 \\
\hline Face width coefficient & $\Phi_{\mathrm{R}}$ & 0.3268 \\
\hline Addendum & $\mathrm{h}_{\mathrm{a}} / \mathrm{mm}$ & 3.825 \\
\hline Dedendum & $\mathrm{h}_{\mathrm{f}} / \mathrm{mm}$ & 4.671 \\
\hline
\end{tabular}

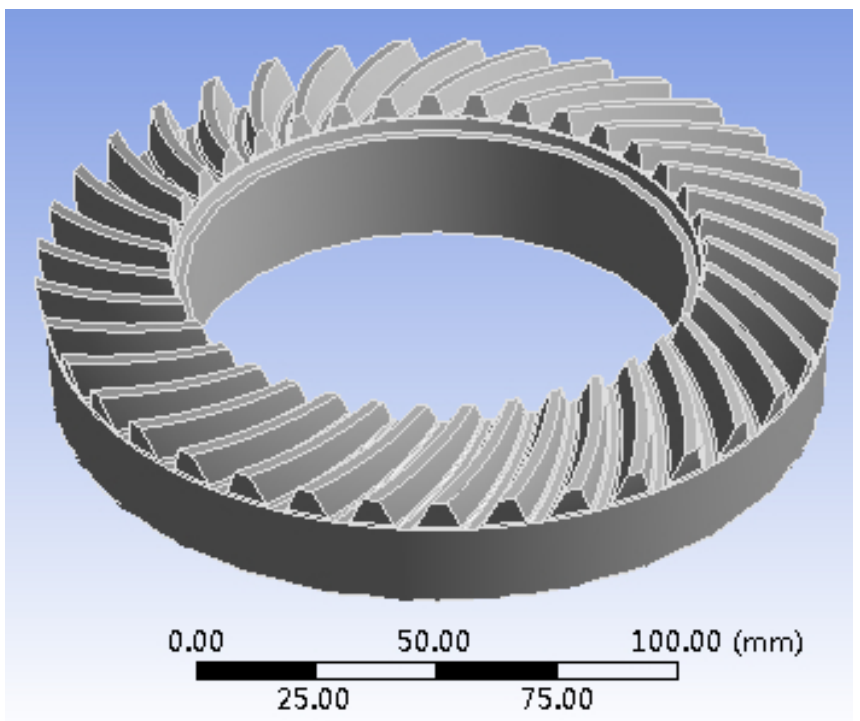

Fig. (1). The geometric model.

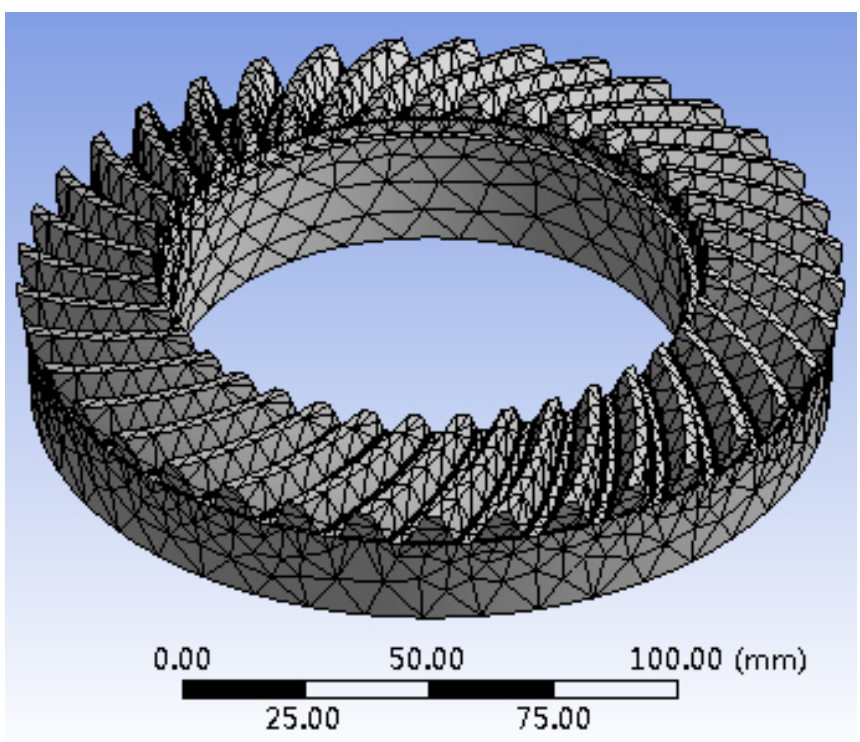

Fig. (2). The finite element model. 
Some parameters of the finite element model are shown in Table 2.

Table 2. Some parameters of the spiral bevel gear wheel finite element model.

\begin{tabular}{|c|c|}
\hline Parameters & Value \\
\hline \hline Element type & Solid187 \\
\hline Material & $20 \mathrm{CrMnTi}$ \\
\hline Modulus of elasticity $/ \mathrm{Pa}$ & $2.06675 \times 10^{11}$ \\
\hline Poisson ratio & 0.3 \\
\hline Density $/\left(\mathrm{kg} / \mathrm{m}^{3}\right)$ & $7.85 \times 10^{3}$ \\
\hline Grid partition type & Free \\
\hline Volume $/ \mathrm{m}^{3}$ & $3.0828 \times 10^{-4}$ \\
\hline Mass $/ \mathrm{kg}$ & 2.420 \\
\hline Node number & 32351 \\
\hline Unit number & 18436 \\
\hline Average of Skewness & 0.5657 \\
\hline Standard deviation of Skewness & 0.2558 \\
\hline
\end{tabular}

\section{FINITE ELEMENT FREE MODAL ANALYSIS}

The free modal analysis of spiral bevel gear wheel which non constraint and load added on the spiral bevel gear wheel was done, and the free modal parameters of the spiral bevel gear wheel was calculated. Usually the resonance more easily occurs at the lower order frequencies. Therefore, solve spiral bevel gear wheel free modal, only expands to the first 12 orders harmonics, and obtain the corresponding frequencies and main vibration mode shapes in this paper. The $1^{\text {st }}$ to $12^{\text {th }}$ orders modal parameters of spiral bevel gear wheel were calculated by using the Lanczos method. The first 6 orders natural frequencies are close to zero, and the corresponding main vibration mode shapes do not appear in obvious deformations, that is to say, the first 6 orders modal are rigid body modals which are three modals along the three-coordinate axes translation and three modals along the three-coordinate axes rotation. The true modals are the $7^{\text {th }}$ to $12^{\text {th }}$ order modals. Remove the first 6 orders rigid modals, then sorted the $7^{\text {th }}$ to $12^{\text {th }}$ order modals accordance to the order of $1^{\text {st }}$ to $6^{\text {th }}$ sequence, the natural frequencies are shown in Table 3.

Table 3. The natural frequencies of the spiral bevel gear wheel.

\begin{tabular}{|c|c|}
\hline Order & Finite Element Method Nature Frequency/Hz \\
\hline \hline The $1^{\text {st }}$ order & 2795 \\
\hline The $2^{\text {nd }}$ order & 2796.3 \\
\hline The $3^{\text {rd }}$ order & 3536.1 \\
\hline The $4^{\text {th }}$ order & 3536.8 \\
\hline The $5^{\text {th }}$ order & 7127.5 \\
\hline The $6^{\text {th }}$ order & 7230.9 \\
\hline
\end{tabular}

Select the $1^{\text {st }}$ to $6^{\text {th }}$ order of natural frequencies, take the overall deformation value as output indicator, create the $1^{\text {st }}$ to $6^{\text {th }}$ order of main vibration mode shape as shown in Figs. $(3,8)$.

Fig. (3) is the $1^{\text {st }}$ order main vibration free mode shape, mainly indicates the 4 nodes bending vibration, the maximum total deformation value is 38.187 units.

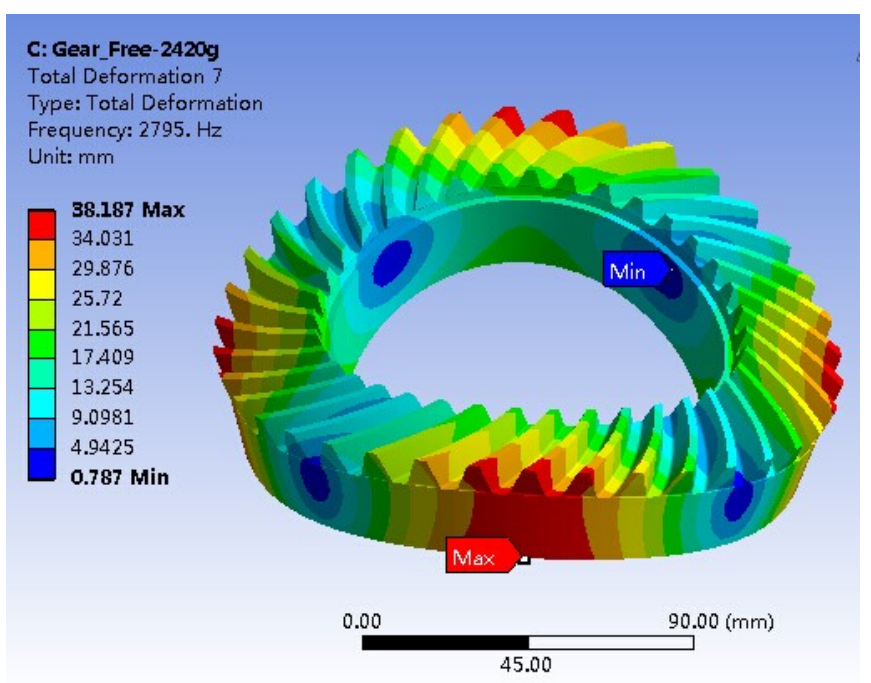

Fig. (3). The $1^{\text {st }}$ order main vibration free mode shape.

Fig. (4) is the $2^{\text {nd }}$ order main vibration free mode shape, mainly indicates the 4 nodes bending vibration, the maximum total deformation value is 38.19 units. From the different value of the $1^{\text {st }}$ order and $2^{\text {nd }}$ order natural frequency is small (only $1.3 \mathrm{~Hz}$ ), the main vibration mode shape animation is very similar and the maximum total deformation value is very close (only 0.003 unit) can be identified that the $1^{\text {st }}$ order and $2^{\text {nd }}$ order should be the same order natural frequency (the experimental results also verified this conclusion later). So, the $1^{\text {st }}$ order and $2^{\text {nd }}$ order natural frequencies should be merged to the new $1^{\text {st }}$ order natural frequency.

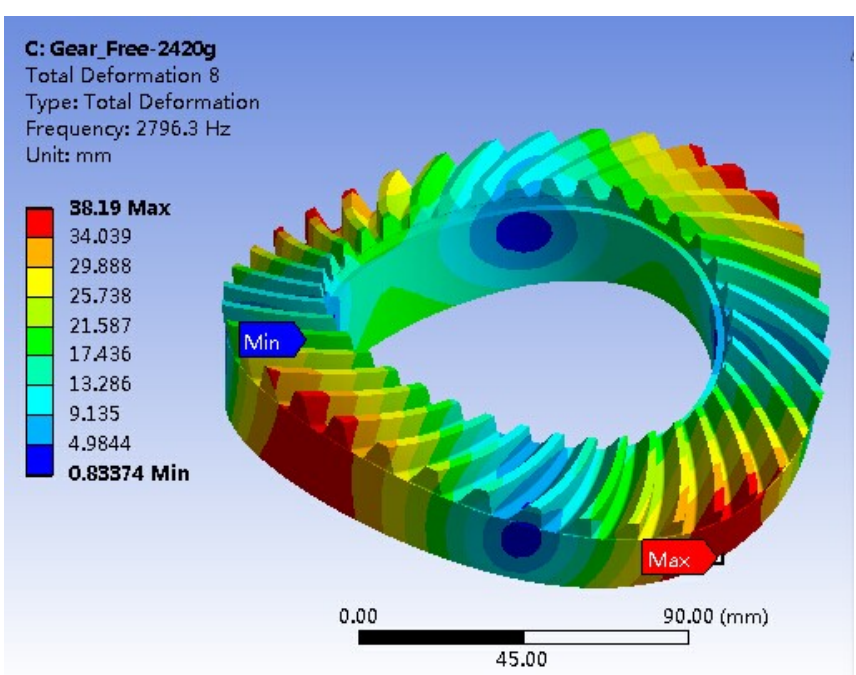

Fig. (4). The $2^{\text {nd }}$ order main vibration free mode shape.

Fig. (5) is the $3^{\text {rd }}$ order main vibration free mode shape, mainly indicates the 4 nodes torsional vibration, the maximum deformation value is 28.724 units. 


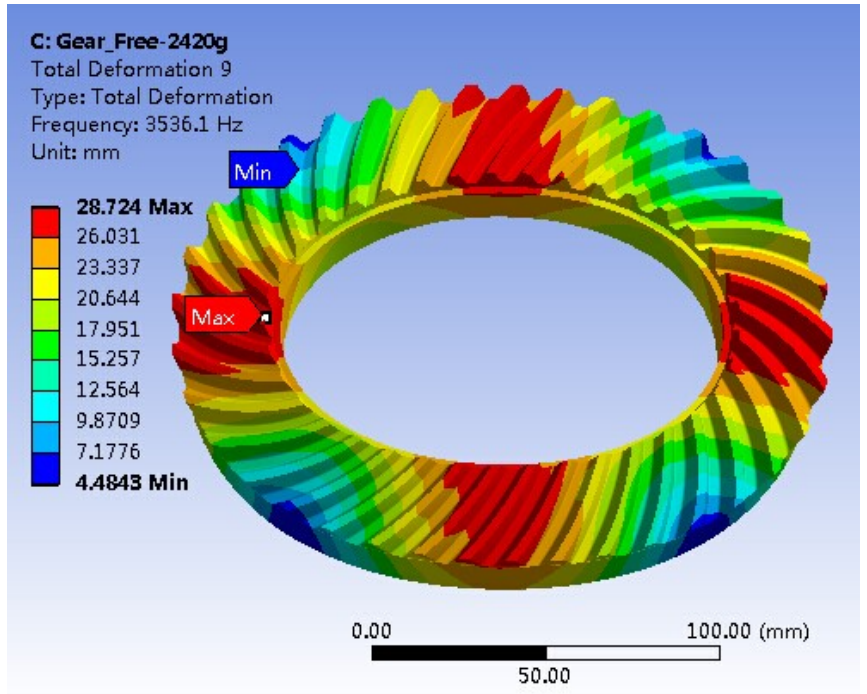

Fig. (5). The $3^{\text {rd }}$ order main vibration free mode shape.

Fig. (6) is the $4^{\text {th }}$ order main vibration free mode shape, mainly indicates the 4 nodes torsional vibration, the maximum total deformation value is 28.729 units. From the difference value of the $3^{\text {rd }}$ order and $4^{\text {th }}$ order natural frequency is small (only $0.7 \mathrm{~Hz}$ ), the main vibration mode shape animation is very similar and the maximum total deformation value is very close (only 0.003 unit) can be identified that the $3^{\text {rd }}$ order and $4^{\text {th }}$ order should be the same order natural frequency (the experimental results also verified this conclusion later). So, the $3^{\text {rd }}$ order and $4^{\text {th }}$ order natural frequencies should be merged to the new $2^{\text {nd }}$ order natural frequency.

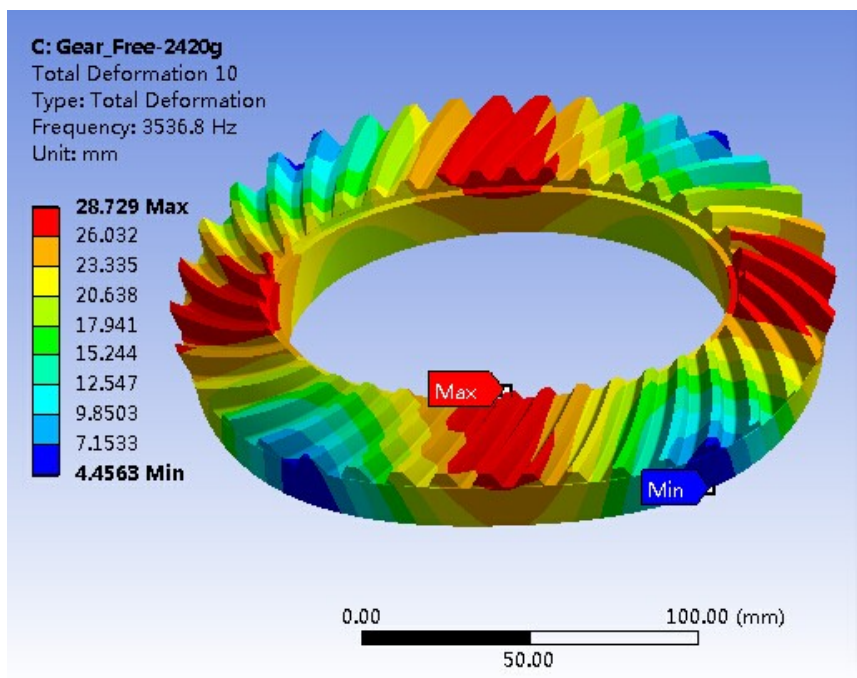

Fig. (6). The $4^{\text {th }}$ order main vibration free mode shape.

Fig. (7) is the $5^{\text {th }}$ order main vibration free mode shape, mainly indicates the umbrella vibration, the main vibration mode shape is similar like an umbrella opening and closing. The maximum total deformation value is 42.501 units. Fig. (7) is the new $3^{\text {rd }}$ order natural frequency because the influence of the last merged mode shape. Fig. $(\mathbf{8})$ is the $6^{\text {th }}$ order main vibration free mode shape, mainly indicates 6 nodes circumferential modals, the maximum total deformation value is 40.194 units.

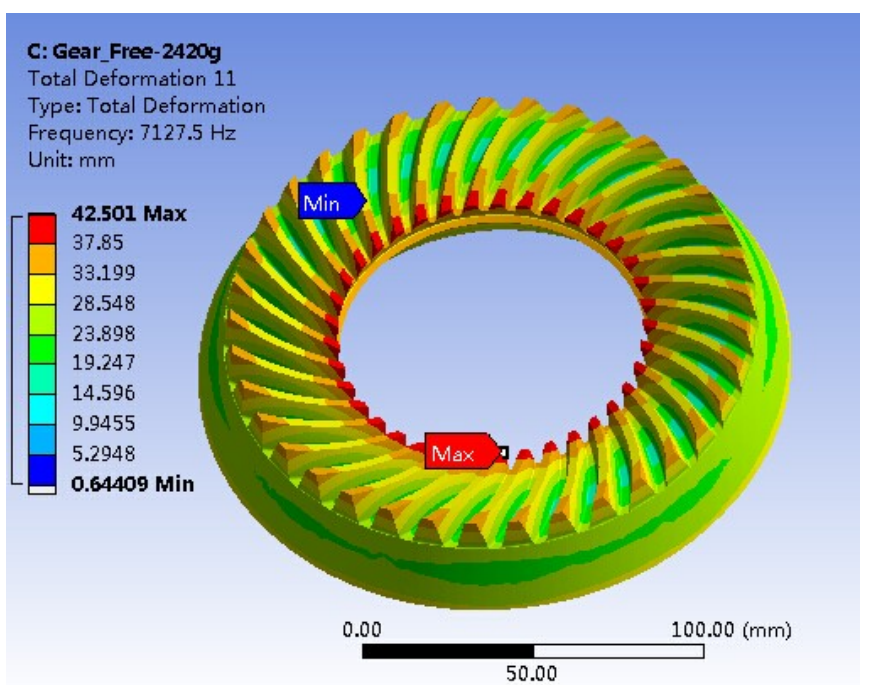

Fig. (7). The $5^{\text {th }}$ order main vibration free mode shape.

Fig. (8) is the new $4^{\text {th }}$ order natural frequency because the influence of the last merged mode shape.

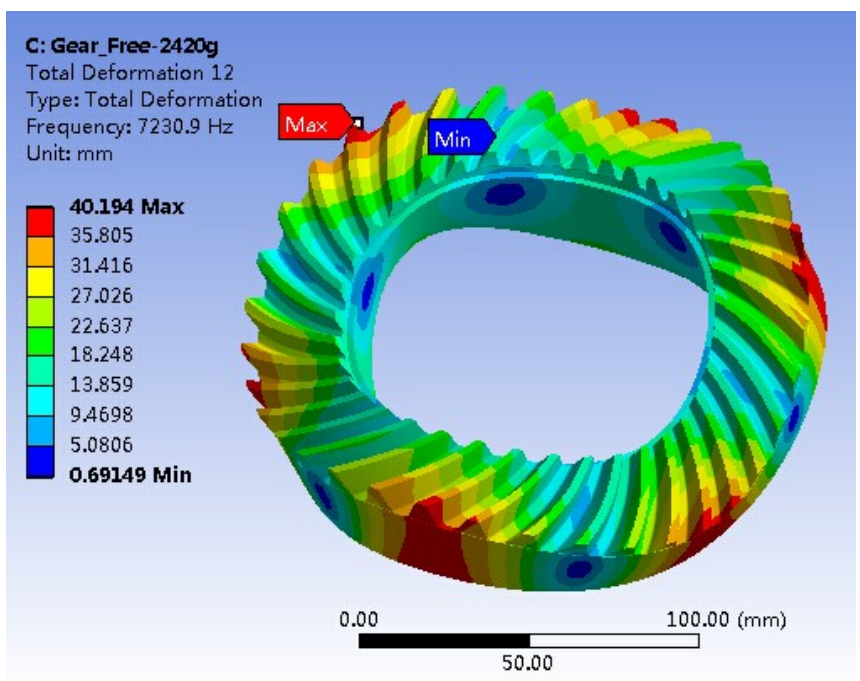

Fig. (8). The $6^{\text {th }}$ order main vibration free mode shape.

\section{THE EXPERIMENT MODAL TEST AND VERIFICATION}

In order to verify the accuracy and effectiveness of the finite element modal analysis results based on the Lanczos method, the impulse force hammer single-point percussion transient excitation and multi-point response free experimental modal test for spiral bevel gear wheel has been done in this paper. The geometric modeling was established by using the 8 points octagon in space to approximate 


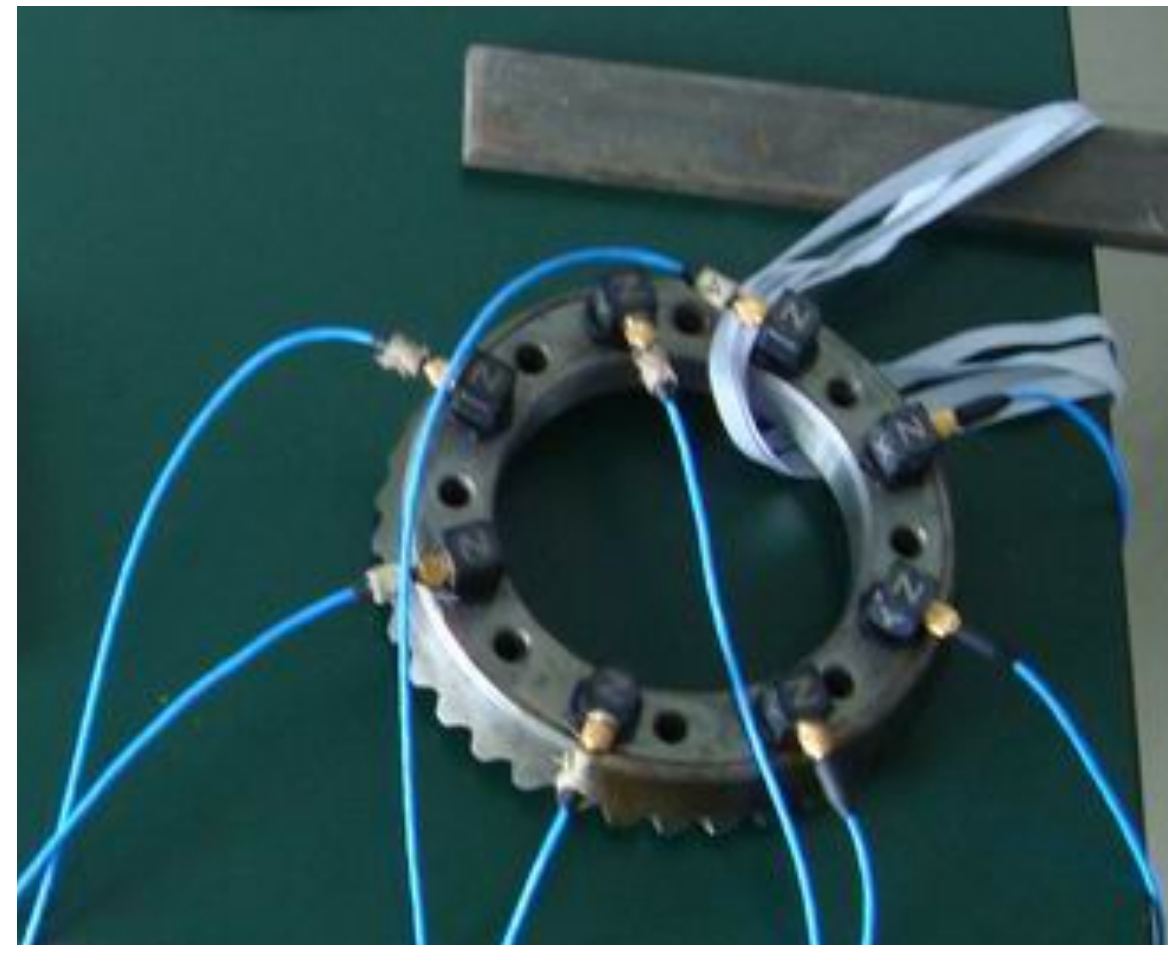

Fig. (9). The layout of sensors.

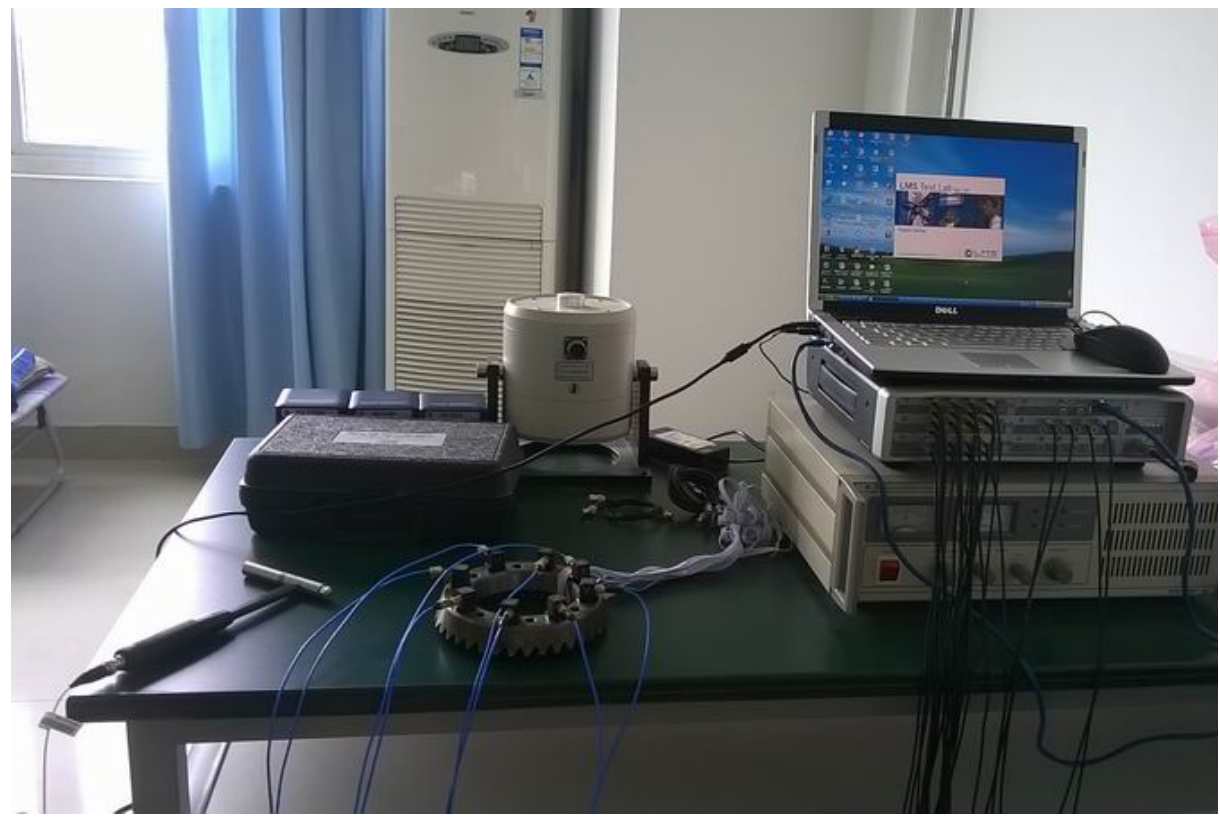

Fig. (10). The layout of experimental modal test.

Table 4. The comparisons of natural frequency.

\begin{tabular}{|c|c|c|c|c|c|}
\hline Order & $\begin{array}{c}\text { Nature Frequency of } \\
\text { Experimental Test/Hz }\end{array}$ & $\begin{array}{c}\text { Nature Frequency of } \\
\text { Finite Element Method/Hz }\end{array}$ & $\begin{array}{c}\text { Damping } \\
\text { Ratio }\end{array}$ & $\begin{array}{c}\text { The Difference/ } \\
\text { Hz }\end{array}$ & $\begin{array}{c}\text { The Relative } \\
\text { Error Rate }\end{array}$ \\
\hline \hline $1^{\text {st }}$ & 2787.48 & 2795.0 & $1.32 \%$ & 7.52 & $0.27 \%$ \\
\hline $2^{\text {nd }}$ & 3522.95 & 3536.1 & $1.56 \%$ & 13.15 & $0.37 \%$ \\
\hline $3^{\text {rd }}$ & 7146.12 & 7127.5 & $2.67 \%$ & 18.62 & $0.26 \%$ \\
\hline $4^{\text {th }}$ & 7260.76 & 7230.9 & $2.89 \%$ & 29.86 & $0.41 \%$ \\
\hline
\end{tabular}


instead the spiral bevel gear wheel outer contour in LMS. IMPACT software. During the experiments, eight number of three-direction acceleration sensors for signal acquisition are installed uniformly on the back of spiral bevel gear wheel, extract the modal parameters through signal processing for modal analysis system.

The experimental hammer use Modally Tuned hammer made by American piezoelectric company with US. Patent No.4.799.375. The eight number of three-direction acceleration sensors also made by American piezoelectric company are uniformly and symmetrical installed on the back of the spiral bevel gear wheel by 502\# glue as shown in Fig. (9).

The support is elastic rope suspension strut and the data acquisition is the LMS SCADA III with 24 channels of acquisition, 2 dedicated channels of speed acquisition, and 2 channels of signal output. The modal analysis system use modal analysis module of the LMS Test lab 9A. The layout of experimental modal test is shown in Fig. (10).

The modal parameters of the $1^{\text {st }}$ to $4^{\text {th }}$ order within the range of $0 \mathrm{kHz}$ to $16 \mathrm{kHz}$ are obtained by the experiment. The comparisons of natural frequency between the finite

element analysis results and the experimental modal test result are shown in Table 4.

The $1^{\text {st }}$ order natural frequency of experimental test is $2787.48 \mathrm{~Hz}$, the damping ratio is $1.32 \%$, the relative error ratio is $0.27 \%$. The $2^{\text {nd }}$ order natural frequency of experimental test is $3522.95 \mathrm{~Hz}$, the damping ratio is $1.56 \%$, the relative error ratio is $0.37 \%$. The $3^{\text {rd }}$ order natural frequency of experimental test is $7146.12 \mathrm{~Hz}$, the damping ratio is $2.67 \%$, the relative error ratio is $0.26 \%$. The $4^{\text {th }}$ order natural frequency of experimental test is $7260.76 \mathrm{~Hz}$, the damping ratio is $2.89 \%$, and the relative error ratio is $0.41 \%$, and all the relative error ratio are the range of the engineering permissible value which is less than $5 \%$.

\section{CONCLUSION}

(1) The three-dimensional solid model of spiral bevel gear wheel was established in the UG NX environment, and the finite element model of spiral bevel gear wheel was built after the definition of material property parameters and grid meshing on the ANSYS Workbench platform.

(2) The free modal analysis of spiral bevel gear wheel has been done by using the Lanczos method for iterative calculation, extract the first 6 orders non zero natural frequencies and the main vibration mode shapes respectively, merged the 2 repeated orders of natural frequencies and obtain the real 4 orders natural frequencies and main vibration mode shapes.

(3) The real first 4 orders of natural frequencies of experimental test for spiral bevel gear wheel are
$2787.48 \mathrm{~Hz}, 3522.95 \mathrm{~Hz}, 7146.12 \mathrm{~Hz}, 7260.76 \mathrm{~Hz}$ respectively by free modal experimental test. The relative error rate of extraction for natural frequencies by using finite element modal analysis based on the Lanczos method are all the range of the engineering permissible value.

\section{CONFLICT OF INTEREST}

The authors confirm that this article content has no conflict of interest.

\section{ACKNOWLEDGEMENTS}

This work supported by the National Natural Science Foundation of China under grant No.51475399 and the Science and Technology Projects JA14239, JA12245 of Education Department of Fujian Province, China.

\section{REFRENCES}

[1] Y. Tang, Z. Q. Zhang, S. L. Tang and Y. Xu, "The mode and vibration response of the double involute gear", Journal of Chongqing University (Natural Science Edition), vol. 29, pp. 6164, October 2006.

[2] B. Wang, and L. Hua, "Dynamic modal analysis of automotive spiral bevel gears with high rotation speed", Automotive Engineering, vol. 33, pp. 447-451, May 2011.

[3] R. Pedersen, I. F. Santos, and I. A. Hede, "Advantages and drawbacks of applying periodic time-variant modal analysis to spur gear dynamics", Mechanical Systems and Signal Processing, vol. 24, pp. 1495-1508, May 2010.

[4] H. Vinayak, and R. Singh, "Multi-body dynamics and modal analysis of compliant gear bodies", Journal of Sound and Vibration, vol. 210, pp. 171-214, February 1998.

[5] S. P. Li, and Z. D. Fang, "Dynamic frequency calculation of the spiral bevel gear under pre-stress", Journal of Aerospace Power, vol. 21, pp. 949-955, May 2006.

[6] S. Li, "Experimental investigation and FEM analysis of resonance frequency behavior of three-dimensional, thin-walled spur gears with a power-circulating test rig", Mechanism and Machine Theory, vol. 43, pp. 934-963, August 2008.

[7] H. Liu, C. L. Wu, and S. Z. Yang, "Calculation and analysis of a mode for helical gear based on FEM", Journal of Huazhong University of Science and Technology, vol. 26, pp. 75-77, November 1998.

[8] S. Li, "Centrifugal load and its effects on bending strength and contact strength of a high speed thin-walled spur gear with offset Web", Mechanism and Machine Theory, vol. 43, pp. 217-239, February 2008.

[9] J. Lin, and R. G. Parker, "Sensitivity of planetary gear natural frequencies and vibration modes to model parameters", Journal of Sound and Vibration, vol. 228, pp. 109-128, January 1999.

[10] W. Xiang, and Y. M. Nie, "A refined shifted block inverse-free Krylov subspace method for symmetric generalized eigenvalue problems", Computers and Mathematics with Applications, vol. 66, pp. 1137-1146, June 2013.

[11] K. J. Bathe, and J. Dong, "Component mode synthesis with subspace iterations for controlled accuracy of frequency and mode shape solutions", Computers and Structures, vol. 139, pp. 28-32, July 2014.

[12] S. A. Arjmandi, and V. Lotfi, "Computing mode shapes of fluidstructure systems using subspace iteration methods", Scientia Iranica, vol. 18, pp. 1159-1169, June 2011. 
[13] A. Nouy, "Generalized spectral decomposition method for solving stochastic finite element equations Invariant subspace problem and dedicated algorithms", Computaional Methods in Applied Mechanical Engineering, vol. 197, pp. 4718-4736, December, 2008.

[14] I. Lenhardt, and T. Rottner, "Krylov subspace methods for structural finite element analysis", Parallel Computing, vol. 25, pp. 861-875, July 1999.

[15] W. Gang, and Z. Lu, "On expansion of search subspaces for large non-Hermitian eigenproblems", Linear Algebraandits Applications, vol. 454, pp. 107-129, August 2014

[16] K. J. Bathe, "The subspace iteration method, Revisited", Computers and Structures, vol. 126, pp. 177-183, September 2013.

[17] C. C. Paige, I. Panayotovb, and J. Zemkec, "An augmented analysis of the perturbed two-sided Lanczos tridiagonalization process", Linear Algebra and its Applications, vol. 447, pp. 119132, April 2014.

[18] T. M. Ericson, and R. G. Parker, "Planetary gear modal vibration experiments and correlation against lumped-parameter and finite element models", Journal of Sound and Vibration, vol. 332, pp. 2350-2375, September 2013.

[19] O. Obe, A. B. Sofoluwe, and O. Abass, "An householder/QL algorithm for the functional eigen problem", Advances in Engineering Software, vol. 4, pp. 148-151, April 1982.

[20] W. Yu, "Dynamics of unsymmetric piecewish-linear/non-linear systems using finite elements in time", Journal of Sound and Vibration, vol. 185, pp. 155-170, January 1995.

[21] F. Rotella, and I. Zambettakis, "Block householder transformation for parallel QR factorization”, Applied Mathematics Letters, vol. 12, pp. 29-34, April 1999.

[22] D. T. Niu, and X. G. Yuan, "A harmonic Lanczos bidiagonalization method for computing interior singular triplets of large matrices", Applied Mathematics and Computation, vol. 218, pp. 7459-7467, July 2012.

[23] D. T. Niu, and X. G. Yuan, "An implicitly restarted Lanczos bidiagonalization method with refined harmonic shifts for computing smallest singular triplets", Journal of Computational and Applied Mathematics, vol. 260, pp. 208-217, April 2014.

[24] K. Browne, S. Z. Qiao, and Y. M. Wei, "A Lanczos bidiagonalization algorithm for Hankel matrices", Linear Algebra and its Applications, vol. 430, pp. 1531-1543, May 2009.

[25] X. S. Wang, Z. Q. Lin, and Z. Chen, "Augmented Lanczos bidiagonalization by small singular value decompositions for face recognition and image compression", International Journal for Light and Electron Optics, vol. 125, pp. 4411-4416, August 2014.

[26] M. Abedi, A. Gholami, G. H. Norouzi, and N. Fathianpour, "Fast inversion of magnetic data using Lanczos bidiagonalization method", Journal of Applied Geophysics, vol. 90, pp. 126-137, March 2013

[27] S. Sundar, B. K. Bhagavan, and A. Datta, "Computing eigenvalues Lanczos algorithm with a new recursive partitioning method", Computers and Mathematics with Applications, vol. 38, pp. 99-107, May 1999.

[28] Z. M. Teng, and R. C. Li, "Convergence analysis of Lanczos-type methods for the linear response eigenvalue problem", Journal of Computational and Applied Mathematics, vol. 247, pp. 17-33, August 2013.

[29] S. Sundar, and B. K. Bhagavan, "Generalized eigenvalue problems: Lanczos algorithm with a recursive partitioning method", Computers and Mathematics with Applications, vol. 39, pp. 211224, July 2000.

[30] H. M. Aktulga, L. Lin, C. Haine, E. G. Ng, and C. Yang, "Parallel eigenvalue calculation based on multiple shift-invert Lanczos and contour integral based spectral projection method", Parallel Computing, vol. 40, pp.195-212, July 2014.

[31] I. Yamazaki, H. Tadano, T. Sakurai, and T. Ikegami, "Performance comparison of parallel eigensolvers based on a contour integral method and a Lanczos method", Parallel Computing, vol. 39, pp. 280-290, June 2013.
[32] Y. Y. Wang, and L. Z. Lu, "Preconditioned Lanczos method for generalized Toeplitz eigenvalue problems", Journal of Computational and Applied Mathematics, vol. 226, pp. 66-76, February 2009.

[33] C. I. Siettos, D. T. Papadopoulos, and A. G. Boudouvis, "Stability analysis of magnetohydrostatic equilibrium by the finite element method and Arnoldi and Lanczos eigensolvers", Advances in Engineering Software, vol. 27, pp. 145-153, January 1996.

[34] Z. X. Jia, "On convergence of the inexact Rayleigh quotient iteration with the Lanczos method used for solving linear systems", Science China Mathematics, vol. 56, pp. 2145-2160, October 2013.

[35] T. Wang, "Theoretical error bounds on the convergence of the lanczos and block-lanczos methods", Computers and Mathematics with Applications, vol. 38, pp. 19-38, September 1999.

[36] R. H. Bisseling, and I. Flesch, "Mondriaan sparse matrix partitioning for attacking cryptosystems by a parallel block Lanczos algorithm - a case study", Parallel Computing, vol. 32, pp. 551-567, July 2006.

[37] D. T. Nguyen, C. F. Bunting, K. J. Moeller, H. Runesha, and J. Qin, "Subspace and Lanczos sparse eigen-solvers for finite element structural and electromagnetic applications", Advances in Engineering Software, vol. 31, pp. 599-606, August 2000.

[38] N. Mohankumar, and T. C. Jr, "A new approach for determining the time step when propagating with the Lanczos algorithm", Computer Physics Communications, vol. 181, pp. 1859-1861, November 2010

[39] L. T. Yang, L. Xu, S. S. Yeo, and S. Hussain, "An integrated parallel GNFS algorithm for integer factorization based on Linbox Montgomery block Lanczos method over GF(2)", Computers and Mathematics with Applications, vol. 60, pp. 338-346, February 2010.

[40] G. $\mathrm{Wu}, \mathrm{W} . \mathrm{Xu}$, and $\mathrm{H}$. Leng, "Inexact and incremental bilinear Lanczos components algorithms for high dimensionality reduction and image reconstruction", Pattern Recognition, vol. 48, pp. 244263, January 2015.

[41] D. Coppersmith, "Solving linear equations over GF(2):block lanczos algorithm", Linear Algebra and its Applications, vol. 192, pp. 33-60, October 1993.

[42] V. Druskin, and L. Knizhnerman, "On application of the Lanczos method to solution of some partial differential equations", Journal of Computational and Applied Mathematics, vol. 50, pp. 255-262, February 1994.

[43] R. Cantó, M. J. Peláez, and A. M. Urbano, "Full rank Cholesky factorization for rank deficient matrices", Applied Mathematics Letters, vol. 40, pp. 17-22, February 2015.

[44] K. Lee, and J. K. Yoo, "Bayesian Cholesky factor models in random effects covariance matrix for generalized linear mixed models", Computational Statistics \& Data Analysis, vol. 80, pp. 111-116, December 2014.

[45] D. J. He, and K. Xu, "Estimation of the Cholesky decomposition in a conditional independent normal model with missing data", Statistics \& Probability Letters, vol. 88, pp. 27-39, May 2014.

[46] P. Benner, and T. Mach, "The LR Cholesky algorithm for symmetric hierarchical matrices", Linear Algebra and its Applications, vol. 439, pp. 1150-1166, April 2013.

[47] Q. Zhang, "Applications of FEM and lanczos algorithm in modal analysis of slender missile", Journal of Projectiles; Rockets; Missiles and Guidance, vol. 27, pp. 61-63, April 2007.

[48] Z. Q. Chen, "Vibration charaeteristies analysis of semi-submerged ship", M.S. thesis, Dalian University of Technology, China, 2011.

[49] Y. Hu, "Tower-belt structural and dynamic characteristics simulation analysis", M.S. thesis, Huazhong University of Science and Technology, China, 2011.

[50] A. H. Mohamed, M. A. Qasem, and M. A. Fathi, "An efficient algorithm for solving higher-order fractional Sturm-Liouville eigenvalue problems", Journal of Computational Physics, vol. 272, pp. 550-558, September 2014.

[51] Z. Peter, "On an inverse eigenvalue problem for a semilinear Sturm-Liouville operator", Nonlinear Analysis: Theory, Methods \& Applications, vol. 68, pp. 639-644, May 2008. 
[52] Z. Z. Bai, "Motivations and realizations of Krylov subspace methods for large sparse linear systems", Journal of Computational and Applied Mathematics, vol. 283, pp. 71-78, August 2015.

[53] F. P. A. Beik, and D. K. Salkuyeh, "On the global Krylov subspace methods for solving general coupled matrix equations", Computers \& Mathematics with Applications, vol. 62, pp. 4605-4613,
December 2011.

[54] G. Barbella, F. Perotti, and V. Simoncini, "Block Krylov subspace methods for the computation of structural response to turbulent wind", Computer Methods in Applied Mechanics and Engineering, vol. 200, pp. 2067-2082, December 2011.

(C) Tieming et al.; Licensee Bentham Open.

This is an open access article licensed under the terms of the (https://creativecommons.org/licenses/by/4.0/legalcode ), which permits unrestricted, non-commercial use, distribution and reproduction in any medium, provided the work is properly cited. 